УДК 502:504.54:911.2:911.52:519.876

КОЭФФИЦИЕНТ ДИНАМИЧНОСТИ ЗА 50 ЛЕТ ДОЛИ КАТЕГОРИЙ ЗЕМЕЛЬ

${ }^{1}$ Мазуркин П.М., ${ }^{2}$ Ефимова Е.А.

${ }^{1}$ Поволжский государственный технологический университет, Йошкар-Ола, e-mail: kaf_po@mail.ru;

${ }^{2}$ Управление Росреестра по Республике Марий Эл, Волжск, e-таil: efimovakalinina@mail.ru

Критерий относительной доли позволяет совместно рассматривать матрицы земельных категорий и их видов угодий. Возможно дополнение долей кадастров и угодий другими относительными параметрами. Коэффициент динамичности доли категорий за 50 лет показывает, что доля площади категорий земельного кадастра дает более достоверную картину динамики поведения землеустроителей в сравнении с измерением площади. По модулю максимумы коэффициента динамичности наблюдаются: 1 категория - 0.0859 в 1996 г.; $2-0.0259$ в $1978 ; 3-0.2171$ в $1998 ; 4-0.0048$ в $1998 ; 5-0.2898$ в 2020; $6-0.0158$ в $1998 ; 7$ категория 4.1887 в 2020 г. Наибольшую динамичность имеют доли земель запаса. При этом очень малую динамичность получают земли особо охраняемых природных территорий. Для анализа динамики категорий земельного кадастра, а затем территориального планирования и прогнозирования необходимы массивы табличных данных площади и долей площади по муниципалитетам страны, причем не менее чем за 50 лет. Идентификация тренда является менее трудоемкой в сравнении с волновой функцией. Тренд у каждой категории нужно будет выявить один раз. Показано, что колебания можно определить по категориям земель до погрешности измерений. Поэтому в землеустройстве наблюдается квантовая определенность разложения динамических рядов на сумму вейвлетов. Этот факт доказывает, что разделение территории на категории кадастра является изобретением человека, а не самой природной среды. Коэффициент динамичности убедительно доказывает, что при условии повышения точности измерений ежегодно должны быть разные значения площади по категориям земельного кадастра.

Ключевые слова: муниципалитет, земли, категории, доля площади, коэффициент динамичности, тренды

\title{
DYNAMIC COEFFICIENT FOR 50 YEARS OF THE SHARE OF LAND CATEGORIES
}

\section{${ }^{1}$ Mazurkin P.M., ${ }^{2}$ Efimova E.A.}

${ }^{1}$ Volga State University of Technology, Yoshkar-Ola, e-mail: kaf_po@mail.ru;

${ }^{2}$ Department of state land supervision of the Rosreestr Administration for the Republic of Mari El, Volzhsk, e-mail: efimovakalinina@mail.ru

\begin{abstract}
The criterion of the relative share makes it possible to jointly consider the matrices of land categories and their types of land. It is possible to supplement the shares of cadastres and lands with other relative parameters. The coefficient of dynamism of the share of categories for 50 years shows that the share of the area of the categories of the land cadastre gives a more reliable picture of the dynamics of the behavior of land surveyors in comparison with the measurement of the area. In modulus, the maxima of the dynamism coefficient are observed: 1 category 0.0859 in $1996 ; 2-0.0259$ in $1978 ; 3-0.2171$ in $1998 ; 4-0.0048$ in $1998 ; 5-0.2898$ in $2020 ; 6-0.0158$ in 1998 ; $7-4.1887$ in 2020 . The shares of reserve lands have the greatest dynamism. At the same time, the lands of specially protected natural areas receive very little dynamism. To analyze the dynamics of the categories of the land cadastre, and then territorial planning and forecasting, arrays of tabular data on the area and shares of the area by municipalities of the country are needed, moreover, for at least 50 years. Identifying a trend is less time consuming compared to a wave function. The trend for each category will need to be identified once. It is shown that fluctuations can be determined by land categories up to the measurement error. In land management, there is a quantum definiteness in the expansion of time series into the sum of wavelets. This fact proves that the division of the territory into cadastre categories is an invention of man, and not of the natural environment itself. The dynamism coefficient convincingly proves that, subject to an increase in the accuracy of measurements, there should be different values of the area by land cadastre categories every year.
\end{abstract}

Keywords: municipality, land, categories, area share, dynamic factor, trends

За рубежом экспериментально исследуется динамика земель во взаимосвязи с другими видами деятельности человека. Например, в [1] дан подход к моделированию динамики земного покрова в зависимости от технологий землепользования. Выявлены связи между социально-экономической динамикой и изменениями в лесном покрове. Этот подход может быть использован для прогнозирования лесного покрова.

Корреляционный анализ между землепользованием и земельным покровом про- веден [2] в муниципальном районе Абуджа (Нигерия) по данным дистанционного зондирования и обработки ГИС по трем космическим снимкам (1986, 2001 и 2016). Было обнаружено, что площадь застройки увеличилась на 246,96 км² $(86,4 \%)$. Также обнаружено, что температура поверхности земли увеличилась в среднем с 23,5 до $30,2^{\circ} \mathrm{C}$. Сильная корреляция между классами земли и температурой наблюдалась на уровне $0.8266,0.9486$ и 0.7700 для трех измерений. Крупные районы были основными факто- 
рами изменений в муниципалитете Абуджа. Для обеспечения теплового комфорта необходима посадка деревьев - вот одна из рекомендаций.

В статье [3] показана связь между классификацией форм рельефа и растительностью на юго-западе провинции Фарс (Иран). Высокая корреляция 0.909 была получена для прогноза высоты деревьев с использованием классификации рельефа. С интенсификацией землепользования возрастает сброс сточных вод, что угрожает качеству поверхностных вод. Виды землепользования представляют разную степень опасности для водных ресурсов [4].

Для сопоставления долей земельных категорий с параметрами климата, рельефа, деревьев, количеством сточных вод и другими факторами вначале необходимо выяснить динамику коэффициента динамичности поведения специалистов в ходе землеустройства.

Цель исследования - методом идентификации [5] выявить закономерности изменения за период в 50 лет, с 1970 до 2020 г., коэффициента динамичности доли распределения земель по категориям кадастра на примере Волжского района Республики Марий Эл (РМЭ).

Из отчетов о распределении земельного фонда Волжского района Республики Марий Эл были выписаны данные (табл. 1) по доле семи категорий кадастра.

Динамика доли земель

Таблица 1 Волжского района, \%

\begin{tabular}{|c|c|c|c|c|c|c|c|c|}
\hline Год & Вре- & \multicolumn{6}{|c|}{ Доля площади земель по категориям } \\
\cline { 3 - 9 } & мя, & 1 & 2 & 3 & 4 & 5 & 6 & 7 \\
\hline 1970 & 0 & 51.55 & 3.11 & 1.19 & - & 41.29 & - & 2.86 \\
\hline 1971 & 1 & 53.05 & 3.11 & 1.31 & - & 41.26 & - & 2.86 \\
\hline$\ldots$ & $\ldots$ & $\ldots$ & $\ldots$ & $\ldots$ & $\ldots$ & $\ldots$ & $\ldots$ & $\ldots$ \\
\hline 2018 & 48 & 45.45 & 3.72 & 1.21 & 19.15 & 27.25 & 2.82 & 0.39 \\
\hline 2019 & 49 & 45.45 & 3.72 & 1.21 & 19.15 & 27.25 & 2.82 & 0.39 \\
\hline 2020 & 50 & 45.45 & 3.72 & 1.21 & 19.15 & 27.25 & 2.82 & 0.39 \\
\hline
\end{tabular}

$j=1$ - сельхозназначения (СХН); 2 - населенных пунктов; 3 - промышленности ...; 4 - особо охраняемых территорий ... (ООПТ); 5 - лесного фонда; 6 - водного фонда; 7 - запаса. С 1992 г. были выделены категории земельного кадастра 4 и 5.

Доли даны по простой формуле:

$$
\alpha_{j}=100 S_{j} / S,
$$

где $\alpha$ - доля, $\%, j-$ код, $S_{j}$ - площадь $j$ категории, $S$ - общая площадь.
Коэффициент динамичности $K$ вычисляется (табл. 2) по формуле

$$
K=\left(\alpha_{F}-\alpha_{T}\right) / \alpha_{T},
$$

где $\alpha_{F}$ - фактическое значение доли площади по категории (табл. 1), га; $\alpha_{T}-$ расчетное по тренду значение доли площади, га. Чем больше $K$, тем динамичнее распределение.

Тренд динамики за 50 лет был выявлен по двухчленной формуле вида

$$
y=a \exp \left(-b x^{c}\right)+d x^{e} \exp \left(-f x^{g}\right),
$$

где $y$ - зависимый показатель, $x$ - влияющая переменная, $a-g$ - параметры модели (3), идентифицируемые в программной среде CurveExpert-1.40 по данным табл. 2.

Идентификация тренда (3) менее трудоемкий процесс в сравнении с волновой функцией. К тому же тренд нужно будет выявить только один раз, так как не требуется идентифицировать асимметричный вейвлет множество раз. Наши исследования показали, что колебания можно определить по категориям земель до погрешности измерений. Поэтому в землеустройстве наблюдается почти полная квантовая определенность разложения динамических рядов на сумму асимметричных вейвлетов. Этот факт еще раз доказывает, что разделение территории на категории является изобретением человека, а не самой природной среды.

По модулю максимумы коэффициента динамичности наблюдаются: 1 категория -0.0859 в 1996 г.; $2-0.0259$ в 1978 ; $3-0.2171$ в $1998 ; 4-0.0048$ в $1998 ; 5-$ 0.2898 в 2020; $6-0.0158$ в 1998; 7 категория - 4.1887 в 2020 г. Наибольшую динамичность имеют доли земель запаса. При этом очень малую динамичность получают земли особо охраняемых природных территорий.

Тренды динамики долей категорий. Параметр общей площади исключается (табл. 3), что позволяет дополнять к долям семи категорий кадастра другие показатели.

Категории земель № 4 и 6 были введены в России только с 1992 года. В итоге эти две категории в табл. 3 также получили меньшие коэффициенты корреляции 0,8835 и 0,8868 . Все тренды по табл. 3 получили уровень адекватности больше 0,7 или сильную связь.

Динамичность доказывается тем, что дополнительно к тренду получено еще множество колебаний, которые, как правило, являются конечномерными асимметричными вейвлетами. Выявление колебаний продол- 
жается почти до ошибки измерений. Тогда можно утверждать, что площади и их доли по категориям земель относятся к вполне определяемым квантам поведения. В связи с этим коэффициент динамичности позво- ляет по тренду вычислять по формуле (2), и это облегчает процесс анализа динамики земель по категориям.

Из рис. 1 исключена категория ООПТ с малым коэффициентом динамичности.

Коэффициент динамичности доли земель Волжского района РМЭ

Таблица 2

\begin{tabular}{|c|c|c|c|c|c|c|c|c|}
\hline Год & Время, & \multicolumn{7}{|c|}{ Коэффициент динамичности доли площади по категориям } \\
\cline { 3 - 9 } & $\tau$ лет & 1 & 2 & 3 & 4 & 5 & 6 & 7 \\
\hline 1970 & 0 & -0.0015 & 0.0083 & -0.1302 & - & -0.0031 & - & -0.0120 \\
\hline 1971 & 1 & -0.0061 & 0.0050 & -0.0400 & - & -0.0039 & - & -0.0120 \\
\hline$\ldots$ & $\ldots$ & $\ldots$ & $\ldots$ & $\ldots$ & $\ldots$ & $\ldots$ & $\ldots$ & $\ldots$ \\
\hline 1992 & 22 & 0.0808 & - & -0.1900 & 0.0017 & -0.2786 & 0.0071 & -0.9734 \\
\hline$\ldots$ & $\ldots$ & $\ldots$ & $\ldots$ & $\ldots$ & $\ldots$ & $\ldots$ & $\ldots$ & $\ldots$ \\
\hline 2018 & 48 & 0.0028 & -0.0017 & 0.0178 & 0.0000 & -0.2731 & -0.0015 & 2.4014 \\
\hline 2019 & 49 & -0.0044 & -0.0038 & 0.0209 & 0.0005 & -0.2821 & -0.0016 & 3.1827 \\
\hline 2020 & 50 & -0.0117 & -0.0059 & 0.0240 & 0.0010 & $\mathbf{- 0 . 2 8 9 8}$ & -0.0016 & $\mathbf{4 . 1 8 8 7}$ \\
\hline
\end{tabular}

Таблица 3

Параметры (3) динамики доли площади по категориям земель Волжского района

\begin{tabular}{|c|c|c|c|c|c|c|c|c|}
\hline \multirow{2}{*}{$\begin{array}{c}\text { Код } \\
\text { категории }\end{array}$} & \multicolumn{7}{|c|}{ Тренд $y=a \exp \left(-b x^{c}\right)+d x^{e} \exp \left(-f x^{g}\right)$} & \multirow{2}{*}{$\begin{array}{c}\text { Коэф. } \\
\text { корр. }\end{array}$} \\
\cline { 2 - 8 } & \multicolumn{2}{|c|}{ Экспоненциальный закон } & \multicolumn{3}{c|}{ Биотехнический закон [3] } \\
\cline { 2 - 8 } & $a$ & $b$ & $c$ & $d$ & $e$ & $f$ & $g$ & \\
\hline 1 & 51.47273 & -0.032345 & 0.70408 & -0.43605 & 1.15916 & 0 & 0 & 0.8986 \\
\hline 2 & 3.08455 & -0.00067961 & 1.28251 & 0.0087425 & 1.48093 & 0.10832 & 0.76742 & 0.9898 \\
\hline 3 & 1.36811 & 0.0025367 & 1.03693 & $8.68802 \mathrm{e}-8$ & 9.23649 & 0.44301 & 1.10285 & 0.9280 \\
\hline 4 & 18.27637 & 0.00062077 & 0.99902 & 0.016715 & 1.52302 & 0.030420 & 1.00024 & 0.8835 \\
\hline 5 & 41.42000 & $5.14420 \mathrm{e}-6$ & 2.85262 & $-6.58250 \mathrm{e}-13$ & 12.93446 & 0.42329 & 1.00769 & 0.9668 \\
\hline 6 & 2.82501 & 0 & 0 & -2.88053 & 0 & 0.00034091 & 2.52720 & 0.8868 \\
\hline 7 & 2.89474 & $2.77216 \mathrm{e}-7$ & 3.01334 & $-1.58695 \mathrm{e}-26$ & 23.07846 & 0.086521 & 1.58504 & 0.9757 \\
\hline
\end{tabular}

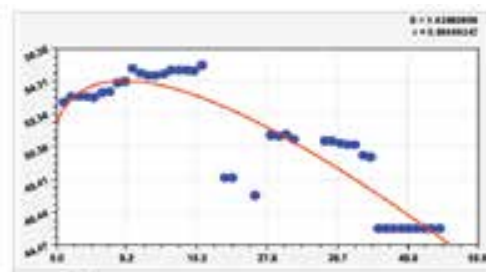

1 -земли сельхозназначения
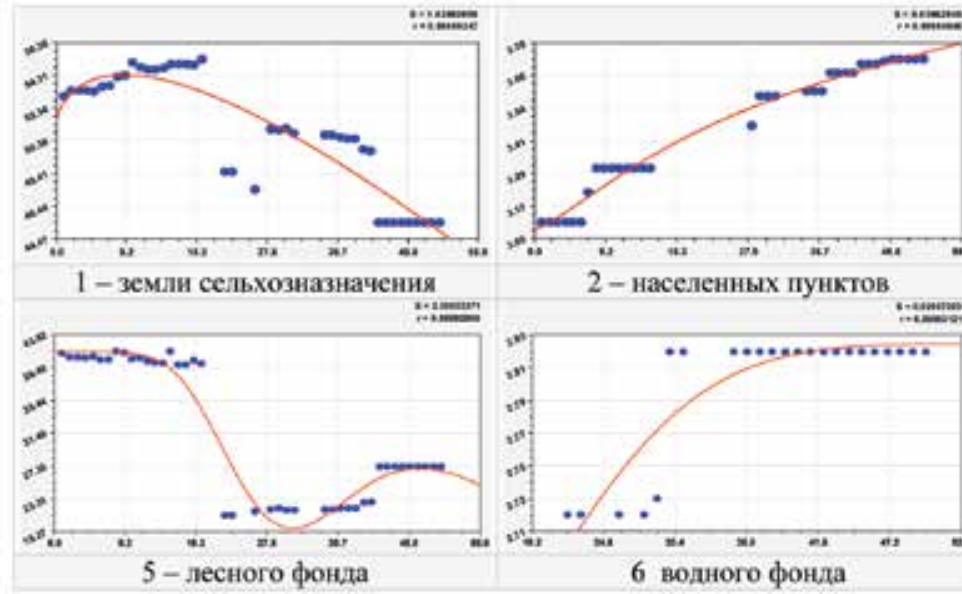

2 - населенных пунктов

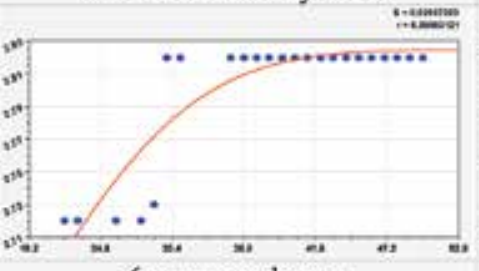

6 водного фонда

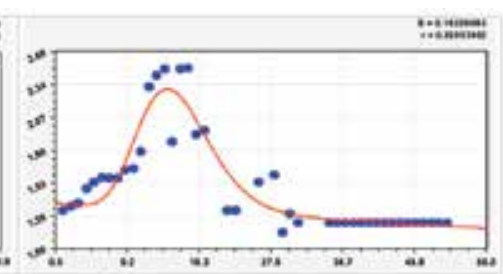

3 - промышленности ... tomenase

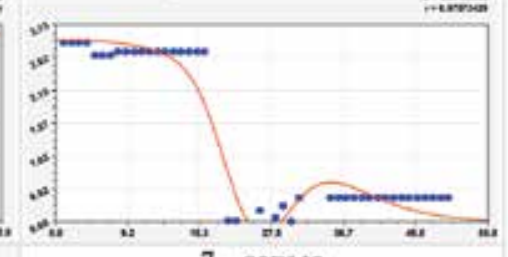

7 - $3 a n a c a$

Рис. 1. Тренды динамики долей категорий земельного фонда Волжсккого района РМЭ с 1970 по 2020 2. (в правом верхнем углу: $S$-стандартное отклонение; $r$-коэффициент корреляции) 
Таблица 4

Параметры (4) коэффициента динамичности (1) долей площади земель Волжского района

\begin{tabular}{|c|c|c|c|c|c|c|c|c|c|c|}
\hline \multirow{3}{*}{$\begin{array}{l}\text { Код } \\
\text { кате- } \\
\text { гории }\end{array}$} & \multirow{3}{*}{$\begin{array}{c}\text { Но- } \\
\text { мер } \\
i\end{array}$} & \multicolumn{8}{|c|}{ Вейвлет $y_{i}=a_{1 i} x^{a_{2 i}} \exp \left(-a_{3 i} x^{a_{4 i}}\right) \cos \left(\pi x /\left(a_{5 i}+a_{6 i} x^{a_{7 i}}\right)-a_{8 i}\right)$} & \multirow{3}{*}{$\begin{array}{l}\text { Коэф. } \\
\text { корр. } \\
r\end{array}$} \\
\hline & & \multicolumn{4}{|c|}{ Амплитуда (половина) колебания } & \multicolumn{3}{|c|}{ Полупериод колебания } & Сдвиг & \\
\hline & & $a_{1 i}$ & $a_{2 i}$ & $a_{3 i}$ & $a_{4 i}$ & $a_{5 i}$ & $a_{6 i}$ & $a_{7 i}$ & $a_{8 i}$ & \\
\hline \multirow[t]{4}{*}{1} & 1 & $7.63146 \mathrm{e}-11$ & 9.69680 & 0.48223 & 0.95573 & 10.58764 & 0.23095 & 0.22766 & 0.77238 & \multirow[t]{2}{*}{0.9424} \\
\hline & 2 & 0.00023654 & 1.62395 & 0.00057009 & 2.08964 & 3.97256 & 0.011516 & 1.08961 & -1.702310 & \\
\hline & 3 & $1.97547 \mathrm{e}-6$ & 3.50977 & 0.11165 & 0.98760 & 1.88124 & 0.011247 & 1.00134 & 0.28354 & 0.5608 \\
\hline & 4 & $9.16728 \mathrm{e}-14$ & 9.33418 & 0.12226 & 1.14793 & 1.36393 & 0.0043571 & 0.98655 & -1.41396 & 0.3585 \\
\hline 2 & 1 & 0.00073338 & 3.82902 & 0.56652 & 0.98352 & 3.45877 & 0.020769 & 1.47778 & 0.91843 & 0.8149 \\
\hline \multirow[t]{8}{*}{3} & 1 & -0.073940 & 0.38457 & 0.055856 & 1 & 5.49613 & $-4.89605 e-7$ & 2.13534 & -0.21550 & \multirow[t]{2}{*}{0.6954} \\
\hline & 2 & 0.00027297 & 3.25269 & 0.27795 & 0.89179 & 2.18825 & 0.13399 & 0.59726 & 1.21603 & \\
\hline & 3 & $-1.15322 \mathrm{e}-6$ & 6.25622 & 0.41 & 0.95484 & 2.02225 & -0.00045409 & 1.69047 & -1.76800 & 0.6891 \\
\hline & 4 & 1.36 & 7.3. & & 1.08419 & 5.90606 & & 0.92 & & 0.4568 \\
\hline & 5 & 0.0 & 1.54799 & & 1.6999 & 0.63147 & 0.04 & 0.68026 & 44 & 0.6712 \\
\hline & 6 & -0.13 & 0 & 2. & 1 & 1.00020 & 0 & 0 & -0.01067 & 0.6722 \\
\hline & 7 & $-5.09532 \mathrm{e}-74$ & 59.01923 & 0.015553 & 2.26974 & 11.29117 & -0.0031889 & 2.23211 & -2.10862 & 0.6667 \\
\hline & 8 & -0.0026239 & 1.66650 & 5 & 0.80062 & 2.74885 & 567 & 1.17231 & 0.26601 & 0.4101 \\
\hline 4 & 1 & 0.00022875 & 2.49031 & 0.20110 & 1.00122 & 5.12809 & 0.017479 & \begin{tabular}{|l|}
1.04278 \\
\end{tabular} & -2.35496 & 0.7664 \\
\hline \multirow[t]{5}{*}{5} & 1 & $1.87292 \mathrm{e}-7$ & 4.45628 & 0.00060479 & 1.00196 & 0.84956 & 0.17579 & 0.98975 & 0.57140 & \multirow[t]{2}{*}{0.9770} \\
\hline & 2 & $1.00411 \mathrm{e}-25$ & 26.09208 & 1.11252 & 1.00065 & 0.46620 & 0.052211 & 1.01140 & 1.36445 & \\
\hline & 3 & $-2.68743 e-24$ & 18.66028 & 0.32626 & 1.08290 & 6.01892 & -0.00082751 & 1.60426 & 2.51011 & 0.6887 \\
\hline & 4 & $9.52462 \mathrm{e}-12$ & 11.08623 & 0.52355 & 1.01320 & 1.08195 & 0.026019 & 1.00200 & 0.42307 & 0.6180 \\
\hline & 5 & -0.0074176 & 1.14414 & 0.12430 & 1.00111 & 38.90826 & 0.10919 & 1.05278 & -3.29726 & 0.5181 \\
\hline \multirow[t]{2}{*}{6} & 1 & 0.0038156 & 3.15096 & & 1.00665 & 6.49030 & -0.00 & 31218 & -2.17480 & \\
\hline & 2 & 0.0 & 3.33750 & 0.23724 & 1.01060 & 3.33170 & -0.0082527 & 1 & -0.041081 & \\
\hline \multirow[t]{5}{*}{7} & 1 & $2.24084 \mathrm{e}-26$ & 15.47109 & 0 & 0 & 0 & 0 & 0 & 0 & \multirow[t]{2}{*}{0.8586} \\
\hline & 2 & $-6.72509 e-45$ & 43.21524 & 0.76385 & 1.20150 & 6.92857 & 0 & 0 & -1.28537 & \\
\hline & 3 & $8.22656 \mathrm{e}-75$ & 66.27260 & 0.83103 & 1.22618 & 1.66825 & -0.0094641 & 0.91045 & -0.37831 & 0.9315 \\
\hline & 4 & $4.14588 \mathrm{e}-33$ & 27.42522 & 0.49802 & 1.09078 & 0.68028 & 0.039600 & 1.05288 & 0.41559 & 0.5369 \\
\hline & 5 & $8.02904 \mathrm{e}-34$ & 37.67122 & 3.09083 & 0.83569 & 0.16161 & 0.021506 & 0.96236 & 1.61731 & 0.850 \\
\hline
\end{tabular}

Вейвлеты коэффициента динамичности. Параметры всех вейвлетов даны в табл. 4.

Изменение во времени коэффициента динамичности имеет волновую природу (табл. 4), и поэтому асимметричные колебания (вейвлет-сигналы) записываются волновой формулой [5] вида

$$
\begin{gathered}
y_{i}=A_{i} \cos \left(\pi x / p_{i}-a_{8 i}\right), \\
A_{i}=a_{1 i} x^{a_{2 i}} \exp \left(-a_{3 i} x^{a_{4 i}}\right), \\
p_{i}=a_{5 i}+a_{6 i} x^{a_{7 i}},
\end{gathered}
$$

где $y$ - зависимый фактор, $i$ - номер составляющей, $m$ - количество членов, $x$ - объясняющая переменная, $a_{1} \ldots a_{8}$ - параметры, получаемые в программной среде CurveExpert-1.40, $A_{i}$ - амплитуда (половина) вейвлета (ось $y), p_{i}$ - полупериод колебания (ось $x$ ).

Динамический коэффициент получил по одному колебанию у доли земель насе- ленных пунктов и особо охраняемых территорий. Два колебания характеризуют поведение доли водного фонда, четыре вейвлета у доли СХН, по пять колебаний у долей земель лесного фонда и земель запаса. Наибольшее количество колебаний (8 шт.) есть у земель промышленности.

Коэффичиент динамичности доли земель СХН. Динамичность доли первой категории кадастра оказалась всего с четырьмя членами, при 18 членах по площади (рис. 2).

Остатки (рис. 2) показывают возможность выявления колебаний с малой амплитудой.

Динамичность доли земель населенных пунктов, ООПТ и водного фонда (рис. 3).

Сильные колебательные возмущения, как правило, были в последней четверти XX столетия. Остатки от вейвлета для населенных пунктов дают возможность выявления колебаний после 2000 г. А остатки от коэффициента динамичности доли ООПТ показывают 
значимость колебаний до 2000 г. Водный фонд в последние 20 лет также успокаивается по динамичности. Этот факт указывает на две возможные причины: 1) действительно земельный фонд Волжского района получил колебательную адаптацию; 2) землеустроители успокоились и стали ежегодно записывать одни и те же значения площади.

Динамичность доли земель промымленности .... Все графики даны на рис. 4.

Вейвлеты № 1, 3, 6-8 получили отрицательный знак, и он указывает на кризис в росте коэффициента динамичности для земель третьей категории земельного кадастра. При этом можно сделать предположение, что периоды колебаний в 1970 г. зависели от циклов солнечной активности. Например, колебания № 1 и 4 почти совпа- дают со средним циклом солнечной активности в 11,3 года. С этим циклом также совпадает вейвлет № 7. Шестой вейвлет является откликом прошлого, то есть наблюдается влияние колебаний до 1970 г.

Коэффициент динамичности третьей категории земель имеет сильные колебания из-за планирования на территории Волжского района, кроме расширения Марийского бумажного комбината, еще ряда других деревообрабатывающих предприятий. Однако марийские леса сильно истощились по хвойным породам, а опыт Финляндии по применению лиственных пород в производстве бумаги так и не был использован. В итоге к настоящему времени произошел сильнейший спад в развитии промышленности Волжского района.

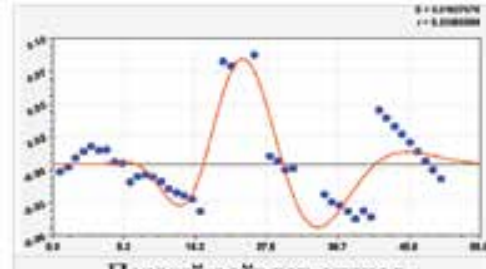

Первый вейвлет-сигнал

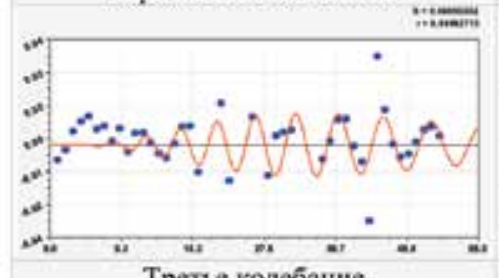

Третье колебание

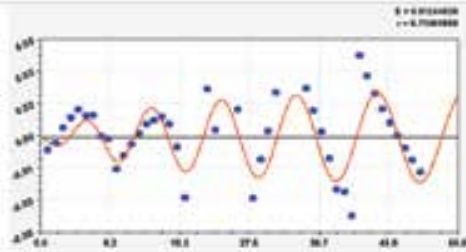

Второй вейвлет-сигнал

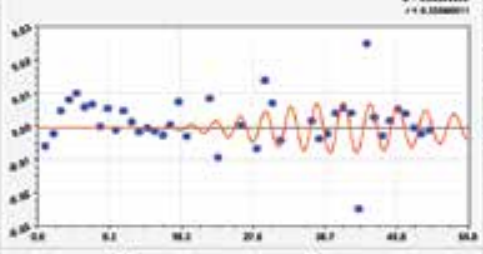

Четвертое колебание

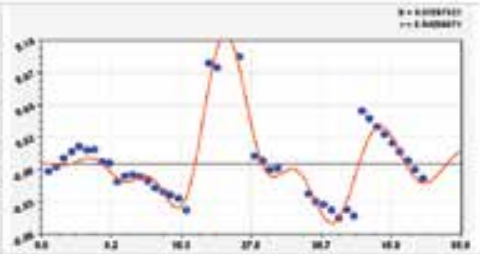

Два вейвлета вместе

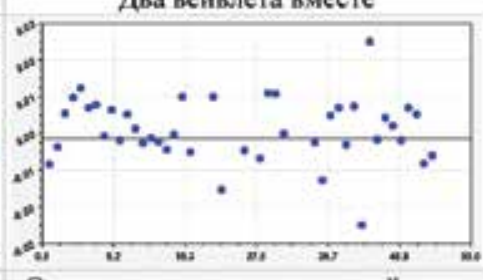

Остатки после четвертого вейвлета

Рис. 2. Коэффициент динамичности распределения доли СХН Волжского района РМЭ (в правом верхнем углу: $S$-стандартное отклонение; $r$ - коэффициент корреляциии)

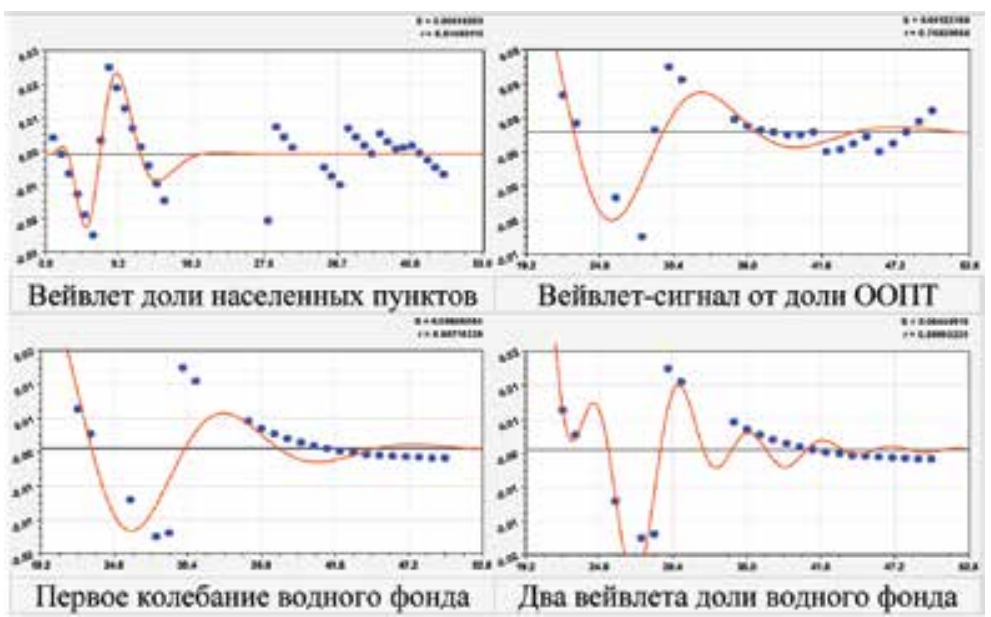

Рис. 3. Динамичность доли земель трех категорий Волжского района РМЭ 


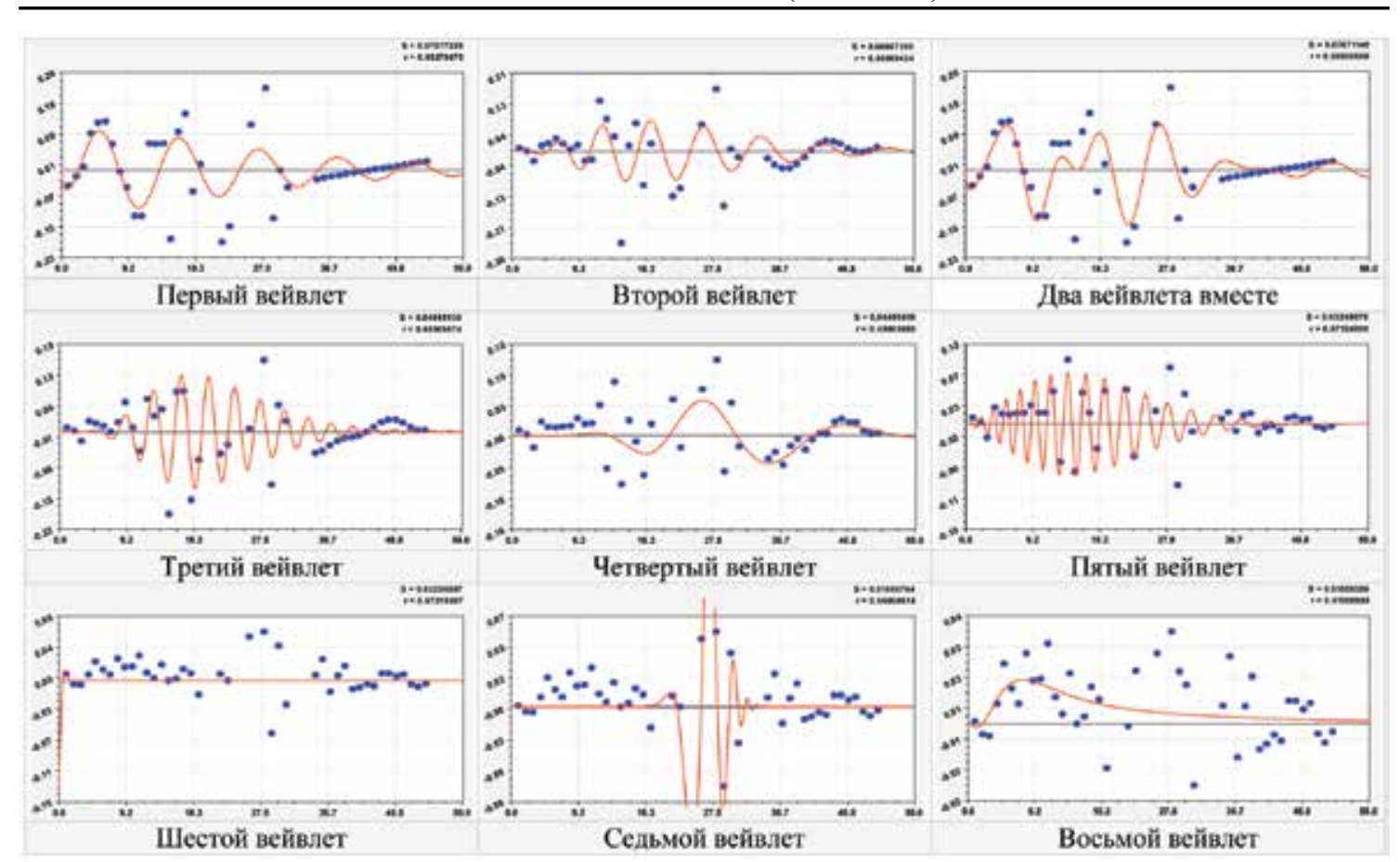

Рис. 4. Коэффициент динамичности доли земель промьиленности Волжского района РМЭ

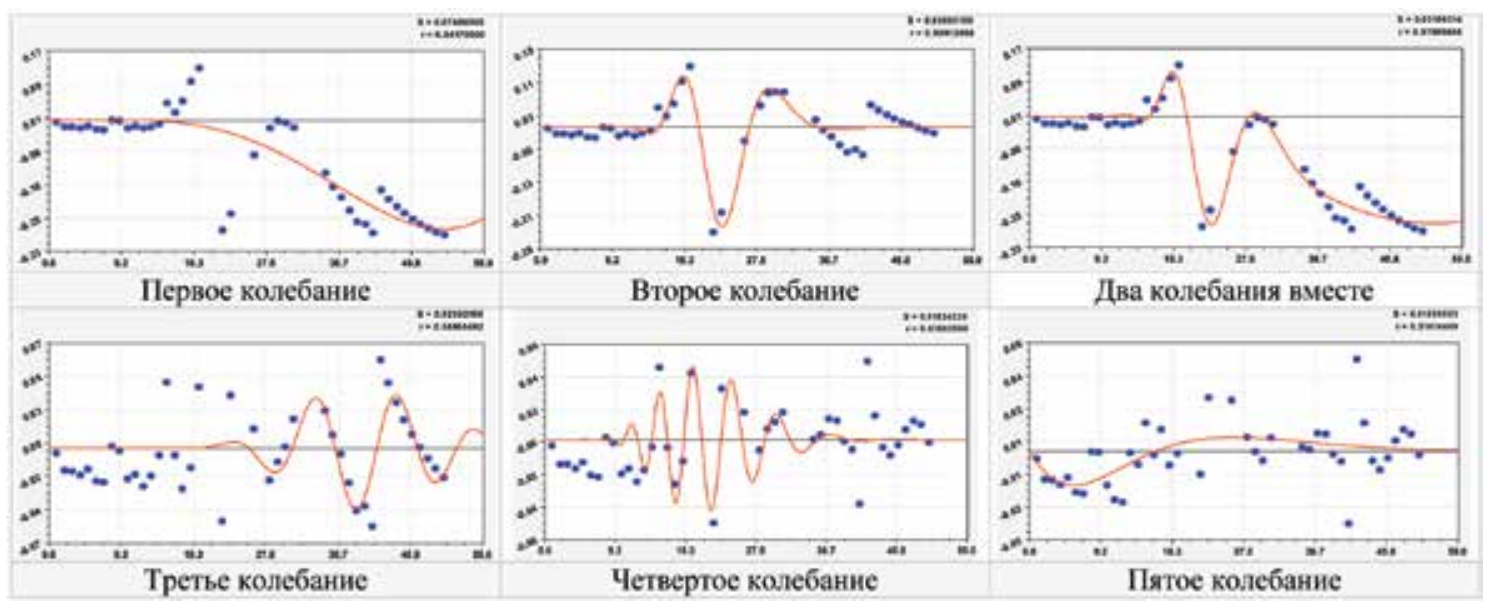

Рис. 5. Коэффициент динамичности доли земель лесного фонда Волжского района РМЭ

Динамичность доли земель лесного фонда. Первое колебание показывает, что слишком сильное колебательное давление оказывалось на леса Волжского района (рис. 5) с 1982 года. На это повлияло планирование города Волжска в советское время как крупного центра глубокой механической и химической технологий переработки древесины.

Первые два вейвлета совместно дают самый высокий коэффициент корреляции 0,9770 . Лесная политика была неустойчивой по второму колебанию с 1982 по 2007 год. Наиболее продолжительным был кризис по пятому колебанию с периодом в 1970 г. около 79 лет. В будущем колебания исключаются, и первое колебание показывает снижение амплитуды.

Коэффиииент динамичности доли земель запаса. Эта категория показывает резкий рост коэффициента динамичности в будущем по закону степенной функции (рис. 6).

По абсолютной площади земли запаса в последние годы получили постоянное значение. Однако тренд на рис. 1 показывает снижение доли запаса. Поэтому нарис.6появляетсяновыйтрендкоэффициента динамичности в виде степенной функции. 


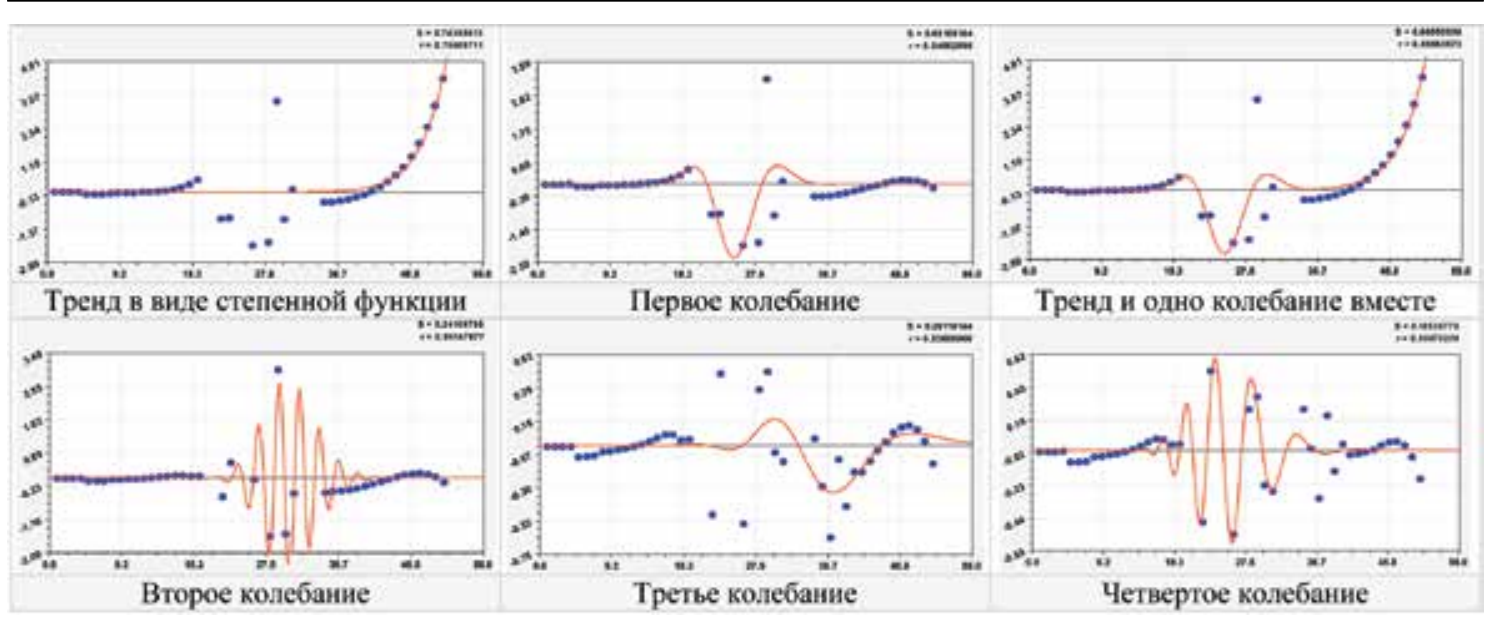

Рис. 6. Коэффициент динамичности доли земель запаса Волжского района РМЭ

Тогда получается, что мониторинг земель фактически каждый год не актуализируется. Аналогично переписываются значения площади и по другим категориям земельного кадастра. Заметно также, что колебательные возмущения остались в прошлом. Поэтому актуальной становится задача повышения точности (снижения погрешности) измерений площади земель по семи категориям кадастра. Это позволит повысить точность вычисления долей в общей площади и снижения коэффициентов динамичности как площади, так и долей по категориям земельного кадастра.

\section{Заключение}

Коэффициент динамичности доли категорий за 50 лет показывает, что относительная доля площади категорий земельного кадастра дает более достоверную картину динамики поведения землеустроителей в сравнении с измерением площади.

Для анализа динамики категорий земельного кадастра, а затем последующего территориального планирования и прогнозирования в Российской Федерации срочно необходимы массивы официальных табличных данных площади и долей площади по всем муниципалитетам страны, причем не менее чем за 50 лет, с 1970 года.

На примере Волжского района РМЭ видно, что переход на доли категорий земельного кадастра дает более достоверную картину изменений коэффициента динамичности.

Идентификация тренда является менее трудоемкой в сравнении с волновой функцией. Тренд у каждой категории нужно будет выявить один раз. Наши исследования показали, что колебания можно определить по категориям земель до погрешности измерений. Поэтому в землеустройстве наблюдается почти полная квантовая определенность разложения динамических рядов на сумму асимметричных вейвлетов. Этот факт доказывает, что разделение территории на категории кадастра является изобретением человека, а не самой природной среды.

Коэффициент динамичности показывает, что при условии повышения точности измерений ежегодно должны быть разные значения площади по категориям земельного кадастра.

Исследование выполнено при финансовой поддержке Российского фонда фундаментальных исследований, Правительства Красноярского края, Красноярского краевого фонда науки в рамках научного проекта: «19-45-240004p_a Прогноз эколого-экономического потенцииала возможных «климатических» миграчиий в Ангаро-Енисейском макрорегионе в меняющемся климате 21 века».

\section{Список литературы / References}

1. Brown D.G., Pijanowski B.C., Duh J.D. Modeling the relationships between land use and land cover on private lands in the Upper Midwest, USA. Journal of Environmental Management. 2000. Vol. 59. DOI: 10.1006/jema.2000.0369.

2. Awuh1 M.E., Japhets, P.O., Officha M.C., Okolie A.O., Enete I.C. A Correlation Analysis of the Relationship between Land Use and Land Cover/ Land Surface Temperature in Abuja Municipal, FCT, Nigeria. Journal of Geographic Information System. 2019. Vol. 11. P. 44-55. DOI: 10.4236/jgis.2019.111004.

3. Mokarram M., Sathyamoorthy D. Relationship between landform classification and vegetation (case study: southwest of Fars province, Iran). Open Geosci. 2016. Vol. 8. P. 302-309. DOI: $10.1515 /$ geo-2016-0027.

4. Seeboonruang U. A statistical assessment of the impact of land uses on surface water quality indexes. Journal of Environmental Management. 2012. Vol. 101. P. 134-142. DOI: 10.1016/j.jenvman.2011.10.019.

5. Mazurkin P.M. Bioclimatic regularities of change in the density of organic carbon of the steppe soil in different regions of the World. Journal of Atmospheric Science Research. 2021. Vol. 04. Is. 01. P. 16-25. DOI: 10.30564/jasr.v4i1.2521. 